\title{
Analisis Pendapatan Peternak Sapi Potong Sistem Pemeliharaan Intensif dan Konvensional di Kabupaten Sleman Yogyakarta
}

\author{
Sundari, A. S. Rejeki dan H. Triatmaja \\ Jurusan Peternakan, Fakultas Pertanian, Universitas Mercu Buana, Yogyakarta
}

\begin{abstract}
ABSTRAK
Penelitian bertujuan untuk mengetahui perbandingan tingkat pendapatan dan kelayakan usaha peternak sapi potong pada system pemeliharaan intensif dengan konvensional di Kabupaten Sleman, Yogyakarta. Materi dan metode yang digunakan berupa 70 responden peternak sapi potong dengan metode survey. Hasil penelitian menunjukkan rata-rata pendapatan peternak system intensif adalah Rp 36.943.964 / tahun atau Rp 3.078.663,7 / bulan dengan rata-rata kepemilikan ternak 8 UT dan pada system konvensional Rp 3.732.135,56 / tahun atau Rp 311.011,3/ bulan dengan ratarata kepemilikan ternak 2 UT. BEP penjualan/ tahun pada system intensif Rp 7.452.162,90 atau BEP volume produksi sapi potong 0,94 unit ternak (UT) dan pada system konvensional Rp 4.283.628,31 atau BEP volume produksi sapi potong 0,56 UT. Nilai rentabilitas usaha ternak sapi potong system intensif 46,3\% dan konvensional 29,9\%, sedang bunga kredit Bank Mandiri sebesar 16\%/tahun. Dapat disumpulkan bahwa usaha penggemukan sapi potong baik system intensif maupun konvensional layak dijalankan.
\end{abstract}

Kata kunci : Pendapatan, peternak, sapi potong, intensif, konvensional

\section{The Income Analysis of Beef Cattle Farmer by Intensive and Conventional System in Sleman Regency Yogyakarta}

\begin{abstract}
The study was purposed to find out income and feasibility of beef cattle farmers by intensive and conventional systems. This evaluation was done May - July 2005. The matter used in this evaluation was 70 beef cattle farmers in Sleman Regency, using survey method. The result showed that beef cattle farmer profit by intensive system was Rp 36,943,964/year or Rp 3,078,663.7/month while by conventional system $R p$ 3,732,135.56 /year or $R p$ 311,011.3/ month. Rentability of beef cattle farmer by intensive system 46,3\% and conventional system 29,9\%. The conclusion indicated that beef cattle farmer both system by intensive and conventional were feasible.
\end{abstract}

Key words: Income, beef cattle farmer, intensive, conventional system

\section{PENDAHULUAN}

Pembangunan peternakan merupakan bagian dari pembangunan nasional, maka dalam menuju sasaran tersebut pelaksanaan pembangunan peternakan harus mampu menyentuh langsung petani peternak. Pembangunan yang mampu menyentuh langsung petani peternak adalah pembangunan yang mampu meningkatkan pendapatan 
peternak (Hadisapoetro, 1978). Populasi peternak sapi potong di kabupaten Sleman tahun 2004 sebanyak 701 orang, 500 diantaranya peternak dengan sistem intensif.

Perkembangan usaha sapi potong di Indonesia melahirkan berbagai inovasi yang pada prinsipnya ditujukan untuk mempercepat pertumbuhan dan meningkatkan pertambahan berat badan harian (PBBH) sapi potong yang digemukkan. $\mathrm{PBBH}$ yang tinggi akan mempercepat waktu pemeliharaan, sehingga sapi dapat dijual lebih cepat dan menguntungkan. Inovasi yang diberikan biasanya dengan memanipulasi pakan. Tidak sedikit macam suplemen yang ditawarkan, produk tersebut dipercaya mampu meningkatkan laju pertumbuhan berat badan.

Salah satu usaha peningkatan pengadaan daging sapi baik dalam kuantitas maupun kualitasnya adalah dengan pemeliharaan sapi secara intensif (feed lot). Pada sistem ini sapi jantan dipelihara di kandang tertentu, tidak dipekerjakan tetapi hanya diberi makan dengan nilai nutrisi yang optimal untuk menaikkan berat badan dan kesehatan sapi yang maksimal. Dengan system ini sapi bobotnya lebih mantap, daging yang dihasilkan akan lebih lunak walaupun kandungan lemaknya menjadi sedikit lebih tebal, kualitas dagingnya sangat baik dan harga jualnyapun tinggi (Abidin, 2002). Pada sistem pemeliharaan konvensional/tradisional peternak hanya memberikan pakan seadanya biasanya jerami dan kadang-kadang rumput tanpa pemberian konsentrat dan suplemen lainnya yang sifatnya dapat mempercepat pertumbuhan, lama pemeliharaan 1 sampai 2 tahun.

Produksi dari suatu ternak adalah hasil interaksi antara genotipe dan faktor lingkungan seperti iklim, nutrisi, penyakit dan praktek manajemen. Keterbatasan produksi ditentukan oleh pakan yang buruk, ketidakseimbangan pakan, penyakit endemik dan parasitisme. Selain pengaruh langsung, terdapat interaksi diantara faktor-faktor tersebut (Tomaszewska et al., 1993). Faktor-faktor yang mempengaruhi produksi sapi potong adalah : jenis bangsanya, umur, kualitas dan kuantitas pakan hijauan maupun konsentrat, penanggulangan penyakit, penanganan pasca panen dan pemasarannya. Dengan keunggulan-keunggulan sistem intensif tersebut dimungkinkan peternak sapi potong intensif akan memperoleh pendapatan yang lebih besar dari pada sistem konvensional.

Berdasarkan uraian di atas, telah diteliti analisis pendapatan peternak sapi potong sistem intensif dan konvensional yang nantinya diharapkan bisa memberikan manfaat sebagai pedoman bagi peternak sapi potong untuk perkembangan dan pengembangan usaha ternak sapi potong.

Tujuan penelitian untuk mengetahui besarnya pendapatan dan kelayakan usaha peternak sapi potong pada sistem pemeliharaan intensif dan konvensional. Manfaat penelitian adalah unntuk mengetahui dan memberikan informasi kepada peternak mengenai besarnya keuntungan antara pemeliharaan sapi potong dengan system intensif dan konvensional dan untuk bahan referensi bagi semua pihak dalam hal pengembangan peternakan sapi potong di kabupaten Sleman.

\section{MATERI DAN METODE}

Materi penelitian yang digunakan dalam penelitian ini adalah peternak sapi potong yang berlokasi di Kabupaten Sleman, DIY. Penelitian ini telah dilakukan pada bulan Mei Juli 2005. Pelaksanaan penelitian dilakukan dengan pengamatan terhadap obyek secara langsung di lapangan dan wawancara dengan bantuan kuesioner untuk mendapatkan data yang diperlukan dengan metode survey.

Dari 17 kecamatan di kabupaten Sleman kemudian diambil sampel responden secara purposive random sampling yaitu 10\% dari 701 peternak. Dari 70 jumlah responden tersebut kemudian diambil sample untuk peternak sapi potong system intensif sebanyak 38 peternak dan untuk peternak sapi potong system konvensional sebanyak 32 peternak. 
Data yang dikumpulkan terdiri dari data primer dan sekunder. Data yang diperoleh langsung dari peternak responden melalui kuisioner dan wawancara, yaitu banyaknya pemberian pakan, biaya pembuatan kandang, data kepemilikan ternak, biaya bibit, biaya tenaga kerja, harga jual pedet, dara dan induk afkir. Data yang diperoleh dari peternak yang berkaitan dengan analisis usaha adalah data selama periode pemeliharaan 1 tahun yaitu dari bulan Juni 2004 - Mei 2005. Rentang waktu ini agar fluktuasi harga sapronak dapat terwakili selama satu tahun produksi. Sedangkan data sekunder meliputi data yang diperoleh dari instansi terkait.

Data keadaan umum daerah penelitian dan identitas peternak responden dianalisis secara deskriptif. Sedangkan data lainnya dianalisis secara ekonomi sebagai berikut :

\section{Analisis pendapatan}

Pendapatan diperoleh dengan
analisis output-input (Riyanto, 1996). Usaha dianggap menguntungkan jika nilai pendapatan positif dan sebaliknya merugi jika nila negatif. Selanjutnya nilai pendapatan dapat dihitung:

$$
\mathrm{P}=\mathrm{TR}-\mathrm{TC}
$$

Keterangan :

$$
\begin{aligned}
\mathrm{P}= & \text { Pendapatan (laba) } \\
\mathrm{TR}= & \text { Total revenue (Penerimaan total/ } \\
& \text { output) } \\
\mathrm{TC}= & \text { Total Cost (Biaya produksi total/ } \\
& \text { input) }
\end{aligned}
$$

\section{Analisis Return Cost Ratio (RCR)}

Apabila nilai RCR lebih dari 1 atau penerimaan total lebih besar dari pada pembiayaan total berarti usaha tersebut menguntungkan. Sebaliknya, jika nilai RCR kurang dari 1 berarti usaha tersebut mengalami kerugian karena penerimaan total kecil dari pada pembiayaan total. Nilai RCR dapat diperoleh dengan perhitungan sebagai berikut :

$R C R=\frac{\text { Re turn }}{\text { Cost }}$

Keterangan :

RCR = Return cost ratio

Return $=$ Penerimaan total

Cost $=$ Pembiayaan total

2. BEP (Break Even Point) merupakan teknik analisis untuk mempelajari hubungan antara Penerimaan, biaya tetap, biaya tidak tetap, keuntungan-kerugian, dan volume kegiatan pada suatu keadaan dimana perusahaan tidak mendapat keuntungan dan kerugian. Termasuk biaya tetap meliputi: penyusutan kandang dan alat, sewa lahan, reparasi rutin, tenaga tetap dan bunga modal. Biaya tetap ini secara totalitas tidak berubah ubah meskipun ada perubahan volume produksi atau penjualan. Biaya variable meliputi: bibit, pakan, kesehatan, pemeliharaan, air dan listrik. Biaya variable ini secara totalitas berubah ubah secara proporsional dengan volume produksi atau penjualan. (Wisnubroto, 1995). Jika total penjualan > BEP penjualan atai volume produksi $>$ dari BEP unit maka usaha dalam kondisi untung dan sebaliknya.

$$
\text { BEP rupiah }=\frac{\text { Biayatetap }}{1-\frac{\text { biaya variabel } / \text { unit }}{H \text { arga jual } / \text { unit }}}
$$

\section{BEP unit =}

\section{Biayatetap}

H arga jual/unit-Biayavariabel/unit

\section{Rentabilitas}

Kelayakan usaha dapat diketahui dengan rentabilitas. Nilai tersebut dibandingkan dengan suku bunga bank yang berlaku, jika nilai rentabilitas lebih besar dari suku bunga maka usaha tersebut 
layak, tetapi sebaliknya jika nilai rentabilitas dibawah suku bunga bank maka usaha tersebut tidak layak (Sutrisno, 1983).

$$
\mathrm{R}=\frac{\mathrm{X}}{\mathrm{Y}} \times 100 \%
$$

Keterangan:

$\mathrm{R}=$ Nilai rentabilitas

$\mathrm{X}=$ Laba usaha

$\mathrm{Y}=\mathrm{B}$

\section{HASIL DAN PEMBAHASAN}

\section{Keadaan Umum Daerah Penelitian}

Kabupaten Sleman berketinggian antara 100 - 2.500 meter dari permukaan air laut, dengan curah hujan rata-rata 15,9-17,1 $\mathrm{mm} /$ tahun dan temperatur udara rata-rata 19,8 $36,2^{\circ} \mathrm{C}$. Produksi rumput gajah pada musim penghujan melimpah sedangkan pada musim kemarau peternak kadang-kadang membeli dari pedagang rumput. Selain itu air untuk ternak cukup mudah yaitu pengairan yang dialirkan ke kandang-kandang peternak melalui selang. Di lokasi penelitian tersebut transportasi mudah.

Wilayah Sleman pada bagian Selatan merupakan dataran rendah yang subur, sedangkan bagian Utara sebagian besar merupakan tanah kering yang berupa ladang dan pekarangan serta memiliki permukaan yang miring dan batas paling Utara gunung Merapi.

\section{Karakteristik Peternak Responden}

Kemampuan peternak sebagai pengelola sangat menentukan tingkat keberhasilan usaha peternakan. Untuk mengetahui kemampuan peternak perlu diketahui latar belakang yang berhubungan dengan keterlibatan mereka dalam mengusahakan ternaknya. Pertimbangan yang digunakan untuk mengetahui kemampuan dalam mengelola ternak sapi potong adalah umur peternak, pengalaman peternak serta tingkat pendidikan.
Tingkat umur mempengaruhi kemampuan fisik petani dalam mengelola usaha taninya, maupun pekerjaan tambahan lainnya. Umur peternak sapi potong sistem intensif ratarata 48,32 tahun sedangkan peternak sapi potong konvensional rata-rata 49,78 tahun keduanya merupakan usia produktif. Hal ini dibutuhkan dalam mengelola ternak maupun lahan pertanian yang cukup kuat. Menurut pendapat Santoso (1979) usia manusia antara 30 sampai 60 tahun mempunyai kemampuan berfikir yang lebih baik sehingga diharapkan dapat mengelola usahanya dengan baik pula.

Komposisi pendidikan peternak sapi potong intensif yang sebagian besar adalah SD yaitu 42,1\% dan pendidikan peternak sapi potong konvensional yang setengahnya adalah SD yaitu 59,4\%. Hal ini menunjukkan daya serap dan pola pikir terhadap ilmu pengetahuan bagi peternak sapi potong masih rendah sehingga sulit untuk mengikuti perkembangan teknologi. Hal ini sesuai dengan pendapat Winarno (1985) yang menyatakan bahwa pendidikan sedikit banyak mempunyai peranan penting terhadap produktivitas peternak dalam mengelola ternaknya.

Peternak sapi potong intensif yang berpengalaman 21-25 tahun sebesar 44,7\%, sedangkan pengalaman beternak sapi potong konvensional 21-25 tahun 46,9. Dengan pengalaman yang cukup lama peternak akan lebih mengerti terhadap usaha yang dikelolanya dan peternak akan lebih mengerti bagaimana cara memelihara ternak untuk mendapatkan hasil yang lebih baik (Kusnadi, 1982).

\section{Biaya, Penerimaan dan laba Usaha Sapi Potong}

Biaya produksi dapat dikelompokkan ke dalam biaya tetap (fixed cost) dan biaya tidak tetap (variable cost). Biaya tetap (fixed cost) adalah biaya yang tidak terpengaruh oleh tingkat kegiatan maupun volume produksi dan biaya tidak tetap (variable cost) adalah biaya yang sifatnya berubah-ubah tergantung volume 
Tabel 1. Biaya , penerimaan dan laba usaha ternak sapi potong system intensif dan konvensional

\begin{tabular}{|c|c|c|c|c|}
\hline & \multicolumn{2}{|c|}{$\begin{array}{c}\text { Sistem pemeliharaan } \\
\text { intensif }\end{array}$} & \multicolumn{2}{|c|}{$\begin{array}{c}\text { Sistem pemeliharaan } \\
\text { konvensional }\end{array}$} \\
\hline & $\begin{array}{l}\text { Jumlah } \\
\text { (Rp) }\end{array}$ & $\begin{array}{l}\text { Persentase } \\
(\%)\end{array}$ & $\begin{array}{l}\text { Jumlah } \\
\text { (Rp) }\end{array}$ & $\begin{array}{l}\text { Persentase } \\
(\%)\end{array}$ \\
\hline \multicolumn{5}{|l|}{ Macam Biaya } \\
\hline \multicolumn{5}{|l|}{ 1. Biaya tetap } \\
\hline Penyusutan kandang & $46.004,49$ & 0,06 & $38.313,24$ & 0,30 \\
\hline Penyusutan alat & 4.973,26 & 0,01 & $3.791,45$ & 0,03 \\
\hline Tenaga kerja & 2.103.157,89 & 0,01 & $1.080 .000,00$ & 8,45 \\
\hline Bunga modal & $149.113,26$ & 0,18 & $129.619,50$ & 1,01 \\
\hline Sewa tanah kandang & $13.233,55$ & 0,02 & $3.691,41$ & 0,03 \\
\hline Jumlah & 2.316.482,46 & 2,85 & $1.255 .415,60$ & 9,82 \\
\hline \multicolumn{5}{|l|}{ 2. Biaya tidak tetap } \\
\hline Bibit & $4.422 .368,42$ & 5,45 & $3.056 .250,00$ & 23,91 \\
\hline Pakan & 73.642.263,16 & 90,68 & 8.398.265,63 & 65,69 \\
\hline Obat/kesehatan & $39.210,53$ & 0,05 & $10.937,50$ & 0,09 \\
\hline TK Tidak Tetap & $576.000,00$ & 0,71 & 0 & 0 \\
\hline Listrik & $216.679,26$ & 0,27 & $64.096,88$ & 0,56 \\
\hline Jumlah & 78.896.521,37 & 97,15 & $11.529 .550,00$ & 90,18 \\
\hline Sub Total Biaya /th & 81.213 .004 & 100 & 12.784 .966 & 100 \\
\hline \multicolumn{5}{|l|}{ Macam Penerimaan } \\
\hline Sapi potong & $58.826 .108,03$ & 99,62 & $16.454 .101,56$ & 99,62 \\
\hline Kotoran & $225.852,63$ & 0,38 & 63.000 & 0,38 \\
\hline Penerimaan / periode & $59.051 .960,66$ & 100 & 16.517.101,56 & 100 \\
\hline Penerimaan / tahun & $118.156 .968,42$ & - & $16.517 .101,56$ & - \\
\hline Pendapatan (laba)/tahun & $36.943 .964,42$ & - & $3.732 .135,56$ & - \\
\hline Pendapatan (laba)/bulan & 3.078.633,70 & - & $311.011,30$ & - \\
\hline
\end{tabular}

Catatan : Rata-rata :

o kepemilikan ternak : intensif 8 UT, konvensional 2 UT.

o Harga jual sapi (Rp) : intensif 7.521.875,00., konvensional 7.501.315,79.

o Harga jual kotoran / truk (Rp) : 80.000,00, (produksi feses $10 \mathrm{~kg} / \mathrm{hari}$.)

o ADG kg/hari : intensif 0,6-0,8, konvensional 0,4-0,6.

o Lama / periode : intensif 0,5 tahun dan konvensional 1 tahun.

Sumber : Data Primer Terolah 2005

produksi. Besarnya biaya tetap dan tidak tetap, penerimaan dan laba usaha ternak sapi potong system intensif dan konvensional selengkapnya dapat dilihat pada Tabel 1.

\section{Analisis Kelayakan Usaha}

Analisis Kelayakan Usaha pada peternak sapi potong dengan sistem intensif dan sistem konvensional dapat dicari dengan rumus sebagai berikut :

\section{Pendapatan diperoleh dengan analisis output-input (Riyanto, 1981)}

Dari Tabel 1 dapat dihitung bahwa laba usaha/responden/tahun pada sistem intensif sebesar Rp 36.943.964,42 atau 3.078.663,7/ bulan dan dengan sistem konvensional Rp 3.732.135,56.atau 311.011,3/ bulan. Sedang laba usaha per unit ternak dengan sistem intensif sebesar Rp 4.614.995,55 sedang dengan sistem konvensional Rp 1.866.067,78. 
UMR di Yogya Rp 680.000,00. Pada responden intensif diatas UMR biasanya sebagai pekerjaan pokok dan konvensional pendapatan dibawah UMR karena biasanya sebagai pekerjaan sampingan.

\section{Analisis Return Cost Ratio (RCR)}

$\mathrm{RCR}=$ return $/$ cost $=$ Penerimaan total $/$

Pembiayaan total

RCR pada peternak sapi sistem intensif adalah

$=118.156 .968,42 / 81.213 .004=1,46$

Sedang, RCR pada peternak sapi import adalah $=16.517 .101,56 / 12.784 .966=1,29$

Dari analisis RCR diatas terlihat bahwa semua sistem pemeliharaan baik intensif maupun konvensional menguntungkan dengan nilai RCR $>$ dari 1.

\section{Analisis Rentabilitas}

Nilai Rentabilitas $=$ (Laba usaha $/$ Biaya produksi total) $\mathrm{x} 100 \%$

Nilai Rentabilitas sistem intensif adalah $=$ $36.943 .964,42 / 81.213 .004 x \quad 100 \%=46 \%$

Nilai Rentabilitas peternak konvensional adalah $=3.732 .135,56 / 12.784 .966 \times 100 \%=29,2 \%$

Dari analisis rentabilitas di atas semua sistem pemeliharaan baik intensif maupun konvensional layak dikerjakan, dikarenakan nilai rentabilitasnya lebih tinggi dari bunga bank yang berlaku di daerah penelitian yaitu bunga kredit ketahanan pangan bank Mandiri $16 \%$ per tahun.

\section{KESIMPULAN DAN SARAN}

Berdasarkan hasil penelitian yang dilakukan terhadap peternak sapi potong dengan sistem intensif dan konvensional di Sleman disimpulkan sbb:

1. Biaya produksi (input) usaha sapi potong dengan sistem intensif sebesar $\mathrm{Rp}$ 81.213.004 / responden / tahun, sedangkan sistem konvensional sebesar Rp 12.784.966 / responden / tahun.

2. Penerimaan (output) usaha sapi potong dengan sistem intensif Rp 118.156.968,42/ responden / tahun, sedangkan konvensional sebesar Rp 16.517.101,56/ responden / tahun.

3. Pendapatan (laba) usaha peternak sapi potong dengan sistem intensif sebesar Rp 36.943.964 / responden / tahun sedangkan usaha sistem konvensional Rp 3.732.135,56/ responden / tahun. Sedangkan laba / unit ternak / tahun dengan sistem intensif sebesar Rp 4.617.995,55 sedangkan konvensional Rp 1.866.067,77

4. Semua sistem pemeliharaan sapi potong baik intensif maupun konvensional layak dikerjakan, dengan nilai rentabilitas lebih dari $16 \%$, pada sistem intensif (46\%) lebih besar dari pada konvensional (29,2\%).

Supaya ada perbaikan manajemen produksi terutama pemilihan bibit dan pemberian pakan yang efisien, perlu dibentuk wadah kelompok usaha sapi potong semacam koperasi, guna efisiensi pengadaan pakan, penyaluran hasil produksi

\section{DAFTAR PUSTAKA}

Abidin, Z. 2002. Penggemukkan Sapi Potong. Agromedia Pustaka. Tangerang.

Hadisaputro, S. 1978. Pola Umum Pertanian Dalam Kaitannya Dengan Pertanian Dengan Lahan Sempit. Agroekonomi. Edisi Maret. Departemen Ekonomi Pertanian Fakultas Pertanian UGM. Jogjakarta

Kusnadi, U. 1982. Analisa Usaha Peternakan Sapi Perah yang tergabung dalam Koperasi di DIY. Tesis, Program S-2. Fak. Peternakan Universitas Gadjah Mada. Yogyakarta.

Riyanto, B. 1996. Dasar-dasar Pembelanjaan Perusahaan. Edisi Keempat. BPFE. Jogjakarta

Santoso. 1979. Analisis Usaha Ternak Sapi Perah di daerah Jawa Tengah dan Jawa Timur. Buletin LPP. No.23 Bogor.

Soetrisno. 1982. Pengantar Ekonomi Perusahaan. Edisi Satu. BPP. UII. Jogjakarta

Tomaszewska, M.I.M. Mastika, A. Djajanegara, S. Gardiner dan T.R. Wiradarya. 1993. Produksi 
Ternak Kambing dan Domba di Indonesia. Sebelas Maret Press. Surakarta

Winarno. 1985. Analisis Manajemen dan Pemasaran Susu Usaha Peternakan Sapi Perah di Kota Madya yogyakarta. Tesis S-2. Fakultas Peternakan Universitas Gadjah Mada Yogyakarta.

Wisnubroto, 1995. Analisis Finansial. Institut Sains dan Teknologi, Yogyakarta. 